\title{
REVIEW
}

\section{Should EOAD patients be included in clinical trials?}

Kinga Szigeti ${ }^{1,2}$ and Rachelle S Doody*2

\begin{abstract}
Alzheimer disease (AD) is a devastating neurodegenerative disease affecting 1 in 68 in the population. An arbitrary cutoff of 65 years as the age of onset to distinguish between early- and late-onset $A D$ has been proposed and has been used in the literature for decades. As the majority of patients develop AD after 65 years of age, most clinical trials address this population. While the early-onset cases represent only $1 \%$ to $6 \%$ of AD cases, this population is the active working subset and thus contributes to a higher public health burden per individual, and early-onset cases are the most devastating at the level of the individual and their families. In this review, we compare and contrast the clinical, neuropsychological, imaging, genetic, biomarker, and pathological features of these two arbitrary groups. Finally, we discuss the ethical dilemma of non-abandonment and justice as it pertains to exclusion of the early-onset AD patients from clinical trials.
\end{abstract}

Alzheimer disease (AD) is the most common form of dementia, affecting 5.5 million people in the US. Progressive neurodegeneration results in relentless cognitive decline, posing a substantial public health burden, and has major implications at the individual level. AD phenotypes are divided into early-onset (EOAD) and late-onset (LOAD) AD with the arbitrary cutoff of 65 years in most studies [1].

Approximately $1 \%$ to $6 \%$ of all $\mathrm{AD}$ is early-onset. Genetics plays a more significant role in EOAD, as this subset is enriched for familial disease in $60 \%$ of the cases [2]. Furthermore, $13 \%$ of EOAD has an autosomal dominant inheritance pattern, and three genes - the amyloid precursor protein $(A P P)$, presenilin 1 (PSEN1), and

\footnotetext{
*Correspondence: rdoody@bcm.edu

${ }^{2}$ Department of Neurology and Alzheimer's Disease and Memory Disorders Center, Baylor College of Medicine, 7200B Cambridge Street, Suite E5.101, Houston,

TX 77030, USA

Full list of author information is available at the end of the article
}

presenilin 2 (PSEN2) - have been identified as having mutations that cause EOAD. These genes contribute to approximately $80 \%$ of the autosomal dominant EOAD cases [2-4]. Although these mutations are rare and affect a small percentage of $\mathrm{AD}$ cases, the discovery of these three genes gave molecular genetic evidence supporting the amyloid hypothesis. As the amyloid cascade is the leading hypothesis, this cohort would be ideal for proofof-principle studies in amyloid-based drug therapy. However, their low prevalence and geographic dispersion make any trial exclusively with familial AD patients logistically challenging. The organization of the Dominantly Inherited Alzheimer Network [5] has been a major accomplishment in creating the logistic basis of such clinical trials, although owing to the small sample size, it is not likely that all drugs can be tested in this specific population.

On clinical grounds, EOAD and LOAD are distinguished on the basis of age of onset (AOO) alone. Several studies attempted to delineate the clinical, neuropsychological, imaging, pathological, and biomarker differences between EOAD and LOAD based on the 65-year arbitrary cutoff proposed by Amaducci and colleagues [1] in 1986. The age of disease onset of patients with $A D$ ranged from 50 to 99 in most studies but included subjects with $\mathrm{AOO}$ as low as 41 years in a few. As AOO is an estimate, the attempt to dichotomize the AOO distribution introduces both misclassification of subjects around the cutoff and noise into the datasets. Furthermore, diverse onset ages within genetically defined families demonstrated that, even with the same upstream trigger, AOO can vary, suggesting that other genetic and environmental factors contribute to the AOO phenotype [6]. In addition, in vivo diagnosis of $\mathrm{AD}$ is estimated at 95\% accuracy, and therefore introduces noise due to some misclassification bias [7]. After consideration of these limitations, there have been few replicable clinical differences between the EOAD and LOAD groups.

Differences in the neuropsychological profiles are controversial and inconsistent between studies. While there is a consensus that LOAD appears to have a more predominant impairment of memory (with verbal memory affected more severely than nonverbal memory in general [8]), it remains unclear whether language, visuospatial abilities, and praxis are more affected or 
preserved in EOAD compared with LOAD [9]. The literature suggested that language is more affected in EOAD with preservation of visuospatial function $[10,11]$, whereas more recently, praxis and visuospatial function appeared to be more affected when compared with LOAD [12]. Most research data support the hypothesis that there is greater involvement of the frontal-parietal structures in EOAD and more predominant deficits in temporal lobe function with a propensity for the left hemisphere in $\operatorname{LOAD}[11,13,14]$.

Studies investigating the rate of disease progression by measuring cognitive and functional abilities over time yielded variable results. Some reports demonstrated that EOAD shows a more rapid progression [15-17], and others found that $\mathrm{AOO}$ is not a major predictor of the rate of progression $[18,19]$.

Most voxel-based volumetric magnetic resonance imaging studies found that, in LOAD, hippocampal atrophy is prominent [20] whereas the pattern in EOAD is more variable. In EOAD, instances of atrophy of the temporal-parietal [21], parietal-occipital [20], temporal and posterior cingulate [22], and precuneus [23] areas have been reported. The variability is likely due to study design, especially the selection of controls. Although there is some agreement that EOAD initially affects mainly the parietal associative cortex and LOAD affects the hippocampus, there are significant variability and overlap between the two groups.

Evidence from brain metabolism studies suggests that EOAD is associated with changes that are more extensive, and studies most commonly report involvement of the precuneus and occipital cortex [24-26], and one study reports extension to the frontal cortex and subcortical grey matter [26]. Recent data indicate that regional or global $\left[{ }^{11} \mathrm{C}\right]$-labelled Pittsburgh compound B binding is similar in early-onset and late-onset patients. In contrast, early-onset patients exhibit glucose metabolism that is significantly lower than that of late-onset patients in precuneus/posterior cingulate, lateral temporo-parietal, and occipital corticies [27]. The autosomal dominant subset of EOAD demonstrates early uptake of Pittsburgh compound $\mathrm{B}$ in the caudate and the putamen $[28,29]$. Amyloid positron emission tomography studies using cerebellar uptake as reference may be confounded because of increased cerebellar uptake in the autosomal dominant subset.

Studies comparing biomarkers in the cerebrospinal fluid in EOAD and LOAD demonstrated that betaamyloid $_{(1-42)}$ level is significantly lower in EOAD as compared with LOAD, with high sensitivity in both groups as a diagnostic marker [30].

Pathological studies demonstrated that the pathological hallmarks of $\mathrm{AD}$ and their regional distribution are similar [31]; however, quantitatively, a higher number of neuritic plaques and neurofibrillary tangles were found for the same severity of dementia in the EOAD group [32-34]. The autosomal dominant subset of EOAD demonstrates gene- and mutation-specific differences in small case series, although all mutations are associated with the typical $\mathrm{AD}$ pathology and fulfill the diagnostic criteria of the Consortium to Establish a Registry for Alzheimer's Disease [35,36].

The above-reviewed literature suggests that EOAD and LOAD are not likely to be fundamentally different, as clinical, imaging, pathological, and biomarker data overlap and various studies have shown variable results; the data rather suggest heterogeneity of AD. Heterogenenity decreases power, and thus one important question is whether including EOAD cases in clinical trials would add to heterogeneity and work against the ability to demonstrate drug-placebo differences. The greatest accumulation of data on disease heterogeneity in $\mathrm{AD}$ involving large cohorts (thousands of cases) exists in genetic datasets. As $\mathrm{AD}$ has high heritability, it is legitimate to look at genetic heterogeneity of $\mathrm{AD}$ since tools are available to study this question and multiple well-designed studies have been reported. The genomewide association studies were early to point out the genetic heterogeneity of $\mathrm{AD}$, showing that each locus has a low attributable risk manifesting in small odds ratios [37-39]. In the comparison of EOAD and LOAD, one of the major differences is in the genetic heterogeneity between the two groups. In EOAD, the heritability is higher and culprit genes have been identified. Mutations in three genes account for $11 \%$ of the genetic causes, and this genetic load is markedly higher than that of the susceptibility genes in LOAD. In LOAD, causative genes have not been identified, and the strongest risk allele is the APOE4 (apolipoprotein E) allele, conferring in the Caucasian population odds ratios of 10 to 14 in homozygotes and around 3 in heterozygotes [40]. Furthermore, incorporating EOAD cases may introduce subjects with mutations in APP, PSEN1, and PSEN2. As most animal models for AD involve mutations in one or a combination of these genes [41], preclinical testing is performed on transgenic animals that in fact model the pathomechanism responsible for $\mathrm{AD}$ in this subset of patients. This group would be the ideal cohort for proofof-principle studies for amyloid targeted therapies, but this is unfortunately precluded by the rarity of mutation carriers. On the other hand, there is no compelling argument in favor of excluding genetic cases, even from trials assessing the efficacy of therapies with a nonamyloid target.

Clinical trial design is regulated and guidelines for the design of clinical trials for $\mathrm{AD}$ were published by the European Medicines Agency (EMEA) [42] and draft guidelines are available in the US and other countries. 
These guidelines do not mention early-onset or genetic $\mathrm{AD}$ as an exclusion criterion. Thus, from a regulatory point of view, there is no reason not to include these patients. The age range for current clinical trials is variable, with age 55,60 , or 65 years often used as the lower limit cutoff for enrollment. As the definition of EOAD is onset at less than 65 years of age, EOAD cases are already enrolled into clinical trials. The EOAD subset that is currently excluded likely represents less than $1 \%$ of all $\mathrm{AD}$ cases and includes the majority of the autosomal dominant cases. The conundrum is that we use transgenic animal models based on the amyloid hypothesis to test compounds for efficacy, and subsequently we exclude the patients whose pathomechanism is closest to the model organism, in which it is most likely that the observed effect is replicated. Furthermore, if this 1\% were to enroll in clinical trials, they would be randomly assigned, like all patients, to drug or placebo and could not substantially alter the outcome of the trial, even if they had a differential response to the treatment. Concerns about a differential safety profile in autosomal dominant EOAD have been raised. As the validity of these concerns are uncertain, safety related to genetic status should be managed in trial design by addressing it in the monitoring procedure and subgroup analysis for the EOAD subset.

Finally, careful consideration of the ethical aspects of exclusion of EOAD patients is warranted. Although the fact is not formally stated, clinical trials exclude EOAD subjects in practice without justification through their inclusion and exclusion criteria. Ethical guidelines stress the importance of considering access to outcomes of research [43] and have established the orphan drug category. The category for orphan drug applies if a drug is intended for the diagnosis, prevention, or treatment of a life-threatening or chronically debilitating condition that affects no more than 5 in 10,000 in the European Community and a disease that affects fewer than 200,000 individuals in the US (according to the Orphan Drug Act) [44]. The EOAD group is estimated to account for $1 \%$ to $6 \%$ of subjects with $\mathrm{AD}$, and EOAD affects 40,000 to 200,000 individuals in the US or 1.2 to 7.4 in 10,000 individuals in the European Community given an estimated AD prevalence of 1 in 68 people. EOAD cases excluded from clinical trials on the basis of the age criterion likely amount to fewer than 200,000 in the US or fewer than 5 in 10,000. The EOFAD (early-onset familial Alzheimer disease) subgroup prevalence is fewer than 1 in 10,000, clearly fulfilling the orphan category criteria. A number of industrialized countries have passed specific legislation defining epidemiological criteria for the designation of orphan status and consequent incentives to counteract the neglect of orphan disease in industrial research [45]. While distribution of resources is a major consideration, many would uphold that society has a moral obligation not to abandon individuals who had the bad luck to be affected by a serious but rare condition for which additional treatments are needed. In addition, medical investigators a professional obligation to advance scientific knowledge. $\mathrm{AD}$ represents a category in which drug development is active, but the orphan subset is excluded from research when these patients in fact might benefit the most, especially from disease-modifying or preventive therapy.

Of the four biomedical ethics principles developed by Beauchamp and Childress [46] - autonomy, nonmaleficence, beneficence, and justice - the principles of autonomy, beneficence, and justice are all relevant for the orphan diseases and for the subset of EOAD cases not currently included in trials. First, autonomy of EOAD subjects is compromised if they wish to contribute to research and are excluded from doing so without justification, and this is the current practice. Second, in regard to the principle of justice, EOAD subjects should have access to and the opportunity to participate in research, and a rights-based approach could further support this claim. Even though the rights-based approach is underrepresented in the literature, its importance is implicit. Third, Landman and Henley [47] proposed a basic moral commitment to non-abandonment which would clearly apply to these young and genetically afflicted individuals who suffer from AD.

Finally, we would like to compare and contrast two ethical theories that conflict in the dilemma of what to do about EOAD subjects: the utilitarian approach, which argues that we seek to maximize the overall good (and do trials involving older, non-genetic $\mathrm{AD}$ patients as they represent the majority of cases), and the deontological approach, in which there is an obligation to show good will irrespective of outcome (thus include EOAD subjects in clinical trials). The utilitarian approach has several weaknesses in this context. To be able to establish that excluding EOAD subjects would maximize overall good, we would need data to support the risks involved when including EOAD cases. The risk implies risk for a negative trial and risk to the individual. We need to estimate the risk for a negative trial imposed by enrolling EOAD subjects to establish that we are maximizing overall good. Heterogeneity would decrease power by decreasing signal-to-noise ratio. However, LOAD is already a heterogeneous disorder and overlaps with EOAD in most characteristics, and thus it is less likely that heterogeneity will increase. In addition, the EOAD subjects would be randomly assigned to active and placebo arms, and this further decreases the problem with a systemic effect. In certain instances (especially in trials of amyloid-based therapies), including EOAD subjects and inherently the autosomal dominant subset may increase power by demonstrating a larger effect in the genotype-specific 
This article is part of a review series on Early-Onset Dementia. Other articles in the series can be found online at http://alzres.com/series/ earlyonsetdementia

cases as compared with the multifactorial sporadic cases. If this is the case, the utilitarian theory in fact would call for including EOAD subjects. We need data to evaluate the risk and benefit, and enrolling EOAD subjects would generate that data. If the protocols address safety issues and $a$ priori protocol design includes subgroup analyses, we would gather data without basically any risk.

In contrast, the deontological approach would concur with the basic moral commitment of non-abandonment of these young individuals devastated by AD. If data from trials enrolling EOAD subjects suggest that there is an increased risk to the trial or to the individual (for example, because of more frequent or severe adverse reactions), the exclusion would have justification and further decisions would be more straightforward. We will not know the answer until we test the hypothesis, and exclusion without justification because of lack of data is ethically unacceptable.

\section{Conclusions}

Enrolling EOAD patients in clinical trials has more benefit than risk involved. Its benefits include potentially increasing the power to detect a signal of efficacy, especially for amyloid-based therapies. The EOAD population is unlikely to increase heterogeneity, as the clinical phenotypes, imaging, brain metabolism, biomarker, and pathological characteristics overlap, and LOAD is already a heterogeneous group. Enrolling these patients is ethical and generates data that will help estimate risk and benefit at the level of the clinical trial and the individual. These risk-benefit estimates will support informed decisions in the future. It is time to stop discriminating against EOAD patients in our joint efforts to prevent and treat AD.

\section{Abbreviations}

$A D$, Alzheimer disease; $A O O$, age of onset; APP, amyloid precursor protein; EOAD, early-onset Alzheimer disease; LOAD, late-onset Alzheimer disease; PSEN1, presenilin 1; PSEN2, presenilin 2.

\section{Competing interests}

The authors declare that they have no competing interests.

\section{Authors' contributions}

KS drafted the manuscript. RSD drafted the outline and edited the draft. Both authors read and approved the final manuscript.

\section{Acknowledgments}

We would like to acknowledge the Mitchell Research Foundation and the patients and caregivers.

\section{Author details}

'Department of Neurology, University of Buffalo, 100 High Street, Buffalo, NY 14203, USA; ${ }^{2}$ Department of Neurology and Alzheimer's Disease and Memory Disorders Center, Baylor College of Medicine, 7200B Cambridge Street, Suite E5.101, Houston, TX 77030, USA.
Published: 8 February 2011

\section{References}

1. Amaducci LA, Rocca WA, Schoenberg BS: Origin of the distinction between Alzheimer's disease and senile dementia: how history can clarify nosology. Neurology 1986, 36:1497-1499.

2. Campion D, Dumanchin C, Hannequin D, Dubois B, Belliard S, Puel M, Thomas-Anterion C, Michon A, Martin C, Charbonnier F, Raux G, Camuzat A, Penet C, Mesnage V, Martinez M, Clerget-Darpoux F, Brice A, Frebourg T: Early-onset autosomal dominant Alzheimer disease: prevalence, genetic heterogeneity, and mutation spectrum. Am J Hum Genet 1999, 65:664-670.

3. Janssen JC, Beck JA, Campbell TA, Dickinson A, Fox NC, Harvey RJ, Houlden H, Rossor MN, Collinge J: Early onset familial Alzheimer's disease: mutation frequency in 31 families. Neurology 2003, 60:235-239.

4. Signorini S, Ghidoni R, Barbiero L, Benussi L, Binetti G: Prevalence of pathogenic mutations in an Italian clinical series of patients with familial dementia. Curr Alzheimer Res 2004, 1:215-218.

5. Dominantly Inherited Alzheimer Network homepage [http://www.dian-info.org].

6. Lleo A, Berezovska O, Growdon JH, Hyman BT: Clinical, pathological, and biochemical spectrum of Alzheimer disease associated with PS-1 mutations. Am J Geriatr Psychiatry 2004, 12:146-156.

7. Joachim CL, Morris JH, Selkoe DJ: Clinically diagnosed Alzheimer's disease: autopsy results in 150 cases. Ann Neurol 1988, 24:50-56.

8. Binetti G, Magni E, Padovani A, Cappa SF, Bianchetti A, Trabucchi M: Neuropsychological heterogeneity in mild Alzheimer's disease. Dementia 1993, 4:321-326.

9. Licht EA, McMurtray AM, Saul RE, Mendez MF: Cognitive differences between early- and late-onset Alzheimer's disease. Am J Alzheimers Dis Other Demen 2007, 22:218-222.

10. Filley CM, Kelly J, Heaton RK: Neuropsychologic features of early- and late-onset Alzheimer's disease. Arch Neurol 1986, 43:574-576.

11. Suribhatla S, Baillon S, Dennis M, Marudkar M, Muhammad S, Munro D, Spreadbury C, Lindesay J: Neuropsychological performance in early and late onset Alzheimer's disease: comparisons in a memory clinic population. Int J Geriatr Psychiatry 2004, 19:1140-1147.

12. Koedam $E L$, Lauffer $V$, van der Vlies $A E$, van der Flier WM, Scheltens $P$, Pijnenburg YA: Early-versus late-onset Alzheimer's disease: more than age alone. J Alzheimers Dis 2010, 19:1401-1408.

13. Maurer K, Volk S, Gerbaldo H: Auguste D and Alzheimer's disease. Lancet 1997, 349:1546-1549.

14. Klünemann HH, Fronhöfer W, Wurster H, Fischer W, Ibach B, Klein HE: Alzheimer's second patient: Johann F. and his family. Ann Neurol 2002, 52:520-523.

15. Jacobs D, Sano M, Marder K, Bell K, Bylsma F, Lafleche G, Albert M, Brandt J, Stern Y: Age at onset of Alzheimer's disease: relation to pattern of cognitive dysfunction and rate of decline. Neurology 1994, 44:1215-1220.

16. Koss E, Edland S, Fillenbaum G, Mohs R, Clark C, Galasko D, Morris JC: Clinical and neuropsychological differences between patients with earlier and later onset of Alzheimer's disease: a CERAD analysis, Part XII. Neurology 1996, 46:136-141.

17. Rogaeva E: The solved and unsolved mysteries of the genetics of earlyonset Alzheimer's disease. Neuromolecular Med 2002, 2:1-10.

18. Drachman DA, O'Donnell BF, Lew RA, Swearer JM: The prognosis in Alzheimer's disease. 'How far' rather than 'how fast' best predicts the course. Arch Neurol 1990, 47:851-856.

19. Bracco L, Gallato R, Grigoletto F, Lippi A, Lepore V, Bino G, Lazzaro MP, Carella F, Piccolo T, Pozzilli C, Glometto B, Amaducci L: Factors affecting course and survival in Alzheimer's disease. A 9-year longitudinal study. Arch Neurol 1994, 51:1213-1219.

20. Frisoni GB, Pievani M, Testa C, Sabattoli F, Bresciani L, Bonetti M, Beltramello A Hayashi KM, Toga AW, Thompson PM: The topography of grey matter involvement in early and late onset Alzheimer's disease. Brain 2007, 130:720-730.

21. Frisoni GB, Testa C, Sabattoli F, Beltramello A, Soininen H, Laakso MP: Structural correlates of early and late onset Alzheimer's disease: voxel based morphometric study. J Neurol Neurosurg Psychiatry 2005, 76:112-114.

22. Shiino A, Watanabe T, Kitagawa T, Kotani E, Takahashi J, Morikawa S, Akiguchi I: Different atrophic patterns in early- and late-onset Alzheimer's disease and evaluation of clinical utility of a method of regional z-score analysis using voxel-based morphometry. Dement Geriatr Cogn Disord 2008, 26:175-186. 
23. Karas $G$, Scheltens P, Rombouts $S$, van Schijndel R, Klein M, Jones B, van der Flier W, Vrenken H, Barkhof F: Precuneus atrophy in early-onset Alzheimer's disease: a morphometric structural MRI study. Neuroradiology 2007, 49:967-976.

24. Salmon E, Collette F, Degueldre C, Lemaire C, Franck G: Voxel-based analysis of confounding effects of age and dementia severity on cerebral metabolism in Alzheimer's disease. Hum Brain Mapp 2000, 10:39-48.

25. Sakamoto S, Ishii K, Sasaki M, Hosaka K, Mori T, Matsui M, Hirono N, Mori E: Differences in cerebral metabolic impairment between early and late onset types of Alzheimer's disease. J Neurol Sci 2002, 200:27-32.

26. Kim EJ, Cho SS, Jeong Y, Park KC, Kang SJ, Kang E, Kim SE, Lee KH, Na DL: Glucose metabolism in early onset versus late onset Alzheimer's disease: an SPM analysis of 120 patients. Brain 2005, 128:1790-1801.

27. Rabinovici GD, Furst AJ, Alkalay A, Racine CA, O'Neil JP, Janabi M, Baker SL, Agarwal N, Bonasera SJ, Mormino EC, Weiner MW, Gorno-Tempini ML, Rosen $\mathrm{HJ}$, Miller BL, Jagust WJ: Increased metabolic vulnerability in early-onset Alzheimer's disease is not related to amyloid burden. Brain 2010, 133:512-528.

28. Koivunen J, Verkkoniemi A, Aalto S, Paetau A, Ahonen JP, Viitanen M, Någren K, Rokka J, Haaparanta M, Kalimo H, Rinne JO: PET amyloid ligand [11C]PIB uptake shows predominantly striatal increase in variant Alzheimer's disease. Brain 2008, 131:1845-1853.

29. Villemagne VL, Ataka S, Mizuno T, Brooks WS, Wada Y, Kondo M, Jones G, Watanabe Y, Mulligan R, Nakagawa M, Miki T, Shimada H, O'Keefe GJ, Masters $\mathrm{CL}$, Mori H, Rowe CC: High striatal amyloid beta-peptide deposition across different autosomal Alzheimer disease mutation types. Arch Neurol 2009, 66:1537-1544.

30. Andreasen N, Hesse C, Davidsson P, Minthon L, Wallin A, Winblad B, Vanderstichele $\mathrm{H}$, Vanmechelen E, Blennow K: Cerebrospinal fluid beta-amyloid(1-42) in Alzheimer disease: differences between early- and late-onset Alzheimer disease and stability during the course of disease. Arch Neurol 1999, 56:673-680

31. McKhann G, Drachman D, Folstein M, Katzman R, Price D, Stadlan EM: Clinical diagnosis of Alzheimer's disease: report of the NINCDS-ADRDA Work Group under the auspices of Department of Health and Human Services Task Force on Alzheimer's Disease. Neurology 1984, 34:939-944.

32. Nochlin D, van Belle G, Bird TD, Sumi SM: Comparison of the severity of neuropathologic changes in familial and sporadic Alzheimer's disease. Alzheimer Dis Assoc Disord 1993, 7:212-222.

33. Bigio EH, Hynan LS, Sontag E, Satumtira S, White CL: Synapse loss is greater in presenile than senile onset Alzheimer disease: implications for the cognitive reserve hypothesis. Neuropathol App/ Neurobio/ 2002, 28:218-227.

34. Marshall GA, Fairbanks LA, Tekin S, Vinters HV, Cummings JL: Early-onset Alzheimer's disease is associated with greater pathologic burden. J Geriatr Psychiatry Neurol 2007, 20:29-33.

35. Jayadev S, Leverenz JB, Steinbart E, Stahl J, Klunk W, Yu CE, Bird TD: Alzheimer's disease phenotypes and genotypes associated with mutations in presenilin 2. Brain 2010, 133:1143-1154
36. Lippa CF, Schmidt ML, Nee LE, Bird T, Nochlin D, Hulette C, Mori H, Lee VM, Trojanowski JQ: AMY plaques in familial AD: comparison with sporadic Alzheimer's disease. Neurology 2000, 54:100-104.

37. Harold D, Abraham R, Hollingworth P, Sims R, Gerrish A, Hamshere ML, Pahwa JS, Moskvina V, Dowzell K, Williams A, Jones N, Thomas C, Stretton A, Morgan AR, Lovestone S, Powell J, Proitsi P, Lupton MK, Brayne C, Rubinsztein DC, Gill M, Lawlor B, Lynch A, Morgan K, Brown KS, Passmore PA, Craig D, McGuinness B, Todd S, Holmes C, et al.: Genome-wide association study identifies variants at CLU and PICALM associated with Alzheimer's disease. Nat Genet 2009, 41:1088-1093.

38. Lambert JC, Heath S, Even G, Campion D, Sleegers K, Hiltunen M, Combarros O, Zelenika D, Bullido MJ, Tavernier B, Letenneur L, Bettens K, Berr C, Pasquier F, Fiévet N, Barberger-Gateau P, Engelborghs S, De Deyn P, Mateo I, Franck A, Helisalmi S, Porcellini E, Hanon O; European Alzheimer's Disease Initiative Investigators, de Pancorbo MM, Lendon C, Dufouil C, Jaillard C, Leveillard T, Alvarez $V$, et al:: Genome-wide association study identifies variants at CLU and CR1 associated with Alzheimer's disease. Nat Genet 2009, 41:1094-1099.

39. Seshadri S, Fitzpatrick AL, Ikram MA, DeStefano AL, Gudnason V, Boada M, Bis JC, Smith AV, Carassquillo MM, Lambert JC, Harold D, Schrijvers EM, RamirezLorca R, Debette S, Longstreth WT Jr., Janssens AC, Pankratz VS, Dartigues JF, Hollingworth P, Aspelund T, Hernandez I, Beiser A, Kuller LH, Koudstaal PJ, Dickson DW, Tzourio C, Abraham R, Antunez C, Du Y, Rotter Jl, et al:: Genomewide analysis of genetic loci associated with Alzheimer disease. JAMA 2010, 303:1832-1840.

40. Corder EH, Saunders AM, Strittmatter WJ, Schmechel DE, Gaskell PC, Small GW, Roses AD, Haines JL, Pericak-Vance MA: Gene dose of apolipoprotein E type 4 allele and the risk of Alzheimer's disease in late onset families. Science 1993, 261:921-923.

41. Elder GA, Gama Sosa MA, De Gasperi R: Transgenic mouse models of Alzheimer's disease. Mt Sinai J Med 2010, 77:69-81.

42. European Medicines Agency homepage [http://www.ema.europa.eu].

43. Council for International Organizations of Medical Sciences: International Ethical Guidelines for Biomedical Research Involving Human Subjects [http:// www.cioms.ch/publications/guidelines/guidelines_nov_2002_blurb.htm].

44. US Food and Drug Administration homepage [http://www.fda.gov].

45. Gericke C, Riesberg A, Busse R: Ethical issues in funding orphan drug research and development. J Med Ethics 2005, 31:164-168.

46. Beauchamp TL, Childress JF: Principles of Biomedical Ethics. Oxford: Oxford University Press; 2001

47. Landmann W, Henley I: Equitable rationing of highly specialized health care services for children: a perspective from South Africa. J Med Ethics 1999, 25:224-229.

doi:10.1186/alzrt63

Cite this article as: Szigeti K, Doody RS: Should EOAD patients be included in clinical trials? Alzheimer's Research \& Therapy 2011, 3:4. 